
\title{
25 Research Soure \\ Perceived stress of clinical practice among associate degree nursing students in Taiwan
}

\section{Chia-Shan Wu}

National Tainan Institute of Nursing

Jiin-Ru Rong ( $\nabla$ rong@ntunhs.edu.tw)

National Taipei University of Nursing and Health Sciences https://orcid.org/0000-0001-6456-1550

Mei-zen Huang

National Tainan Institute of Nursing

Research article

Keywords: Nursing students, Clinical practice, Perceived Stress, Decision tree

Posted Date: August 17th, 2020

DOI: https://doi.org/10.21203/rs.3.rs-55550/v1

License: (1) This work is licensed under a Creative Commons Attribution 4.0 International License. Read Full License 


\section{Abstract}

Background: Clinical placements play an important role in helping nursing students to achieve clinical competence, but these placements can be highly challenging and stressful. This study aimed to examine factors associated with perceived stress of clinical practice and to investigate the effect of health status on perceived stress.

Methods: This was a cross-sectional quantitative study conducted among 724 associate nursing degree students in Southern Taiwan.

Results: Health status scores varied from 28-139, with an average of 68.40 (SD = 25.75). Perceived stress scores ranged from $0-95$ points with an average score of 36.65 (SD \pm 15.95$)$. Factors linked to perceived stress were general health status, practice subject, practice grade, gender, and sleeping hours. The CART analysis showed health status as the most important predictor to perceived stress.

Conclusions: General health status can be used as a measure to predict vulnerability to stress and to identify students who are most vulnerable.

\section{Introduction}

Clinical placements play an important role in helping nursing students to achieve clinical competence, and to develop elements of professional practice in real world scenarios. These placements help students to gain practical experience in taking care of patients and to attain a gradual sense of belonging to the nursing profession, whilst improving their socialization skills and professional role confidence [1-2]. The first clinical placement is considered to be of paramount importance within nursing students' educational and professional journey.

While the merits of clinical practice for healthcare students is well established in general, these placements can also be highly challenging and stressful [3-5] and for some nursing students, the perceptions and experiences are markedly inconsistent with the desired outcome [6]. Studies have widely recognised that the transition from being a nursing student to a practitioner working with real patients, involves a range of experiences from just being uncomfortable to undergoing a reality shock along with feelings of self-doubt and inadequacy coupled with discouragement and exhaustion [5, 7-9]. Studies have shown that most students experienced stress due to reasons such as their inability to put clinical theory into practice; fear of making the wrong decisions; unfamiliarity with applying professional knowledge; lack of confidence in implementing clinical skills; poor communication between patients, family members, and professional team members; distrust of patients and their families; pressure during acute medical situations, and poor time management [10-15]. The transition to clinical practice during placement is also indicated to be a great source of anxiety and fear with students experiencing high levels of physical exertion and fatigue due to the pressure from professional interest and expectations [16-19]. Stress during clinical placements may lead to physical and psychological symptoms such as frequent headaches, anxiety, nervousness, poor sleep, lack of attention, cognitive decline, and learning 
difficulties, that reduce the ability to provide clinical care, and may even affect their willingness to work as a nurse in future $[11,13,20-26]$.

A number of intrinsic personal factors have been linked to experiences of stress among students in general including low self-esteem, low self-confidence, inadequate decision making abilities, poor selfcontrol, tendency to self-blame and poor social behaviours [17, 27-29]. While general health status has been indicated as one of the potential factors linked to stress during clinical placement, studies have rarely been able to differentiate the impact of general health status on the levels of stress experienced during the placement.

In Taiwan, clinical placement constitutes a key component of the nursing program with the aim of providing nursing students with the essential practical skills of a registered nurse. In order to be able to register as a nurse in Taiwan, nursing students are required to complete a program of 1,016 hours of clinical placement in teaching hospitals approved by the Ministry of Examination [30]. After completing the course requirements, nursing students normally undergo a rotational placement through each placement unit for one year before graduation. This placement is indicated to have beneficial impact on Taiwanese nursing students' professional development. For example, a qualitative study exploring nursing students' perceptions towards the nursing profession based on their experiences of clinical placement in a baccalaureate nursing program indicated that clinical practicum facilitated baccalaureate nursing students' psychological development and professional knowledge. The experiences gained in real clinical situations during clinical placement helped nursing students to clarify their misconceptions about the nursing profession and to recognize the true nature of the profession while developing cognitive and skill based competencies [31]. Another study on perceived stress and physio-psycho-social status of nursing students during the initial period of clinical practice in Taiwan reported that stress for these students came mainly from the lack of professional knowledge and skills and the most common response to stress was manifestation of social behavioural symptoms [32]. A cross-sectional study of 357 nursing diploma students found that higher perceived stress, female sex, and an introverted personality trait were significant independent factors of physio-psycho-social symptoms during their clinical placement [33]. Studies have, however, been unable to differentiate the impact of general health status on the level of stress experienced during clinical placement.

In order to help nursing students cope with the stress of clinical placement and complete their programs more smoothly, there is a need for more effective indicators along with a model that can accurately predict internship stress during placement. The aim of this study was to examine factors associated with perceived stress of clinical practice and to investigate whether a decision-tree algorithm, specifically the Classification and Regression Tree (CART) model, could be used to develop an accurate prediction model of internship stress especially to predict the effect of health status on perceived stress during clinical practice.

\section{Methods}


This was a cross-sectional quantitative study conducted among senior students in a five-year associate nursing degree program in a nursing school in Southern Taiwan.

\section{Participants /Sample}

The participants comprised of senior students in a five-year associate nursing degree program of a nursing school in southern Taiwan. A convenience sampling approach was used to recruit the participants. The inclusion criteria for participation were that they were either in the fourth or fifth year of the program, in the clinical placement phase where they spend either full or half year in clinical practice; they did not have any severe physical or mental health problems as diagnosed by a physician; and they were not dealing with a family crisis during the data collection period as reported by a clinical instructor.

According to the "Basic Information of Schools at All Levels" of the Statistics Department of the Ministry of Education [34], the school has a total of 1,939 registered students in 2019. The estimated sample size was calculated according to the following formula [35]:

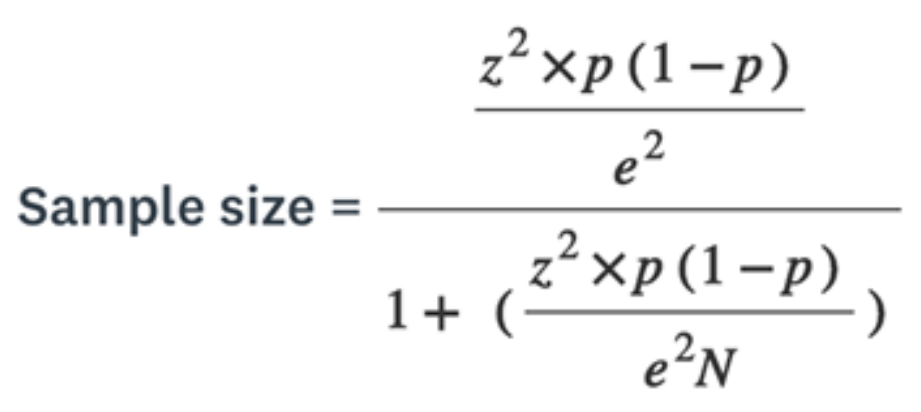

Assumptions were made as follows: the probability of performing good or bad in students' clinical practice was $p=0.5$, the sampling error was $e=39$ and the confidence level was 0.95 , and sample size was calculated to be 689 . With an additional $10 \%$ nonresponse rate, the final sample size was calculated to be 758 .

\section{Data collection tools}

The study instruments included the Perceived Stress Scale for Nursing Students in Clinical Practice [36] and the General Health Questionnaire - 28 [37]. The Perceived Stress Scale, originally developed by Sheu et al. [36] is designed to understand the extent and type of stress as perceived by nursing students in Taiwan. The Scale consisted of 29 items to measure perceived stress, grouped into six domains including: the stress of providing nursing care to patients; stress from teachers and the nursing staff; stress of dealing with paper work and the workload of clinical nursing; stress of dealing with peers and others; stress of demonstrating the mastery of professional knowledge and skills, and stress of the practicum work environment. Each item was graded on a 5-point Likert scale 0 = "never," 1 = "rare," 2 = 
"sometimes," 3 = "frequent," and 4 = "always." The higher the score, the higher the perceived stress. The reliability, content validity and construct validity the test has been demonstrated by Sheu et al. [36].

The Chinese version of the General Health Questionnaire (GHQ) -28 $[37,38]$ was used to assess the participants' physical and mental health in the past month. The GHQ-28 is a self-administered instrument, developed based on an exploratory factor analysis (EFA) of the original GHQ-60. Although it was originally developed in English, the questionnaire has been translated into different languages, including Chinese [38], and the stability of the factor structures has been evaluated across different cultures and samples [39-41]. The 28-item GHQ consist of four subscales with 7-items each: somatic symptoms, anxiety and insomnia, social dysfunction and severe depression [37]. The participants indicated symptoms related to their health in general over the past month, using the items on a 5-point Likert scale as follows: never (score $=1)$, less than usual (score $=2)$, as usual $($ score $=3)$, more than usual $($ score $=4)$, much more than usual (score $=5$ ) with higher score showing worse physical and mental health status. The scores were then grouped into three categories to indicate the health status: scores 28-55 (good health), scores 56-83 (moderate health) and scores $\geqq 84$ (poor health).

\section{Data collection}

After gaining ethics approval, the researchers explained the study's purpose and methods to potential participants. Those who were interested to take part after the initial discussion were given detailed information about the study, and what the participation involved. A written consent was taken before they were enrolled in the study. The self-administered questionnaires including the Perceived Stress Scale for Nursing Students and the General Health Questionnaire (GHQ) - 28 were sent to the participants by post with a prepaid envelope for return. During the course of the study, any participant could withdraw from the study without affecting their placement or studies. Before analysis, the participants were given the opportunity to request their data to be deleted even though they had completed the questionnaires. The data analysis started only after receiving confirmation from participants that they agreed to continue to be part of the study. Students who participated were offered a fluorescent pen as a reward for their time.

\section{Ethical considerations}

Ethical approval of the study was obtained from the Ethics Committee of National Cheng Kung University (NCKU HREC-E-105-113-2). The researchers explained the study's purpose and methods to potential participants. Those who were interested to take part after the initial discussion were given detailed information about the study in a cover letter, and what the participation involved. The researchers assured the participants that the information collected will be kept confidential and anonymous. Potential participants were also made aware of their right to refuse to participate in or to withdraw at any stage during the course of the study.

\section{Statistical analysis}


The Statistical Package for the Social Sciences 23.0 was used to perform the statistical analysis. Data were summarized as mean and standard deviation for continuous variables. The variables were normally distributed. The Pearson's correlation coefficient was used to analyse associations, with $p$ values $<.05$ regarded as significant. A multi-factor analysis of variance (ANOVA) procedure was performed for group comparisons.

A classification and regression tree (CART) analysis was conducted on risk factors of internship stress using the following potential predictors: general health status, internship category, grade of intern, gender and sleeping hours. CART is an explanatory technique that has been widely used to reveal data structure, identify important characteristics, and develop decision trees [42]. The CART model is composed of three main steps: (1) CART initialization: generating a decision tree based on training data set; (2) CART pruning and optimization: the regression tree is pruned according to constraints, such as the maximum depth of the tree, the minimum sample size of the leaf node and the node's minimum impurity as the model has best generalization through the combination of different parameters that generated different CART models - the maximum depth of the tree ( $\max$ depth), the minimum sample number of leaf nodes (min_samples_leaf), the minimum impurity of the nodes (min_impurity_split) (3) CART prediction: put the test set into the trained model and creating prediction [43].

The CART analysis was conducted in three steps: 1. A classification model was constructed from the entire sample to create the largest tree structure with the minimum sample of the parent code as 100 and the minimum sample of the child node as $50 ; 2$. The correct rate of the classification model was evaluated by using $\mathrm{K}$ - fold cross-validation with the value set at 10; 3 . The maximum difference in risk was used in post-pruning and the value was set to 0 in order to generate the tree structure with minimum risk value. A decision node was taken as the point for making the decision, with the branches drowning from a node representing the possible alternatives or courses of action available at that point. The set of alternatives were considered mutually exclusive and collectively exhaustive [44-46].

\section{Results}

\section{Demographic characteristics}

A total of 790 questionnaires were distributed to eligible respondents in the associate nursing degree program and 724 completed questionnaires were returned with an overall response rate of $91.6 \%$. The demographic characteristics of the participants are presented in Table 1. The majority of participants were females $(96.7 \%)$. Their average age was 19.13 (SD \pm 0.42 ) years and a great majority $(79.4 \%)$ were in the final year of the degree programme. While more than half of the students $(57.6 \%)$ reported their sleeping hours as $6-8$ hours, $39.8 \%$ of the students slept for less than 5 hours per day. The practice areas included Medical Surgical Nursing, Obstetrics Nursing, Paediatrics Nursing, Psychiatric Nursing and Community Nursing. 
Table 1

Demography data $(\mathrm{N}=724)$

\begin{tabular}{|lll|}
\hline Variable & Numbers & $\%$ \\
\hline Gender & & \\
\hline Male & 24 & 3.3 \\
\hline Female & 700 & 96.7 \\
\hline Practice grade & 149 & 20.6 \\
Fourth grade & & \\
\hline Fifth grade & 575 & 79.4 \\
\hline Quality sleep (hours) & & \\
\hline $9-10$ & 11 & 1.5 \\
\hline $6-8$ & 417 & 57.6 \\
\hline $4-5$ & 288 & 39.8 \\
\hline $1-3$ & 8 & 1.1 \\
\hline
\end{tabular}

\section{Nursing students' health status}

The health status scores among the participants varied from 28 to 139, with higher score indicating worse health status. The average score was $68.40(S D=25.75)$. The worst health status was reported on domains of anxiety and insomnia (Mean: 24.97; SD: \pm 4.35 ) and social dysfunction (Mean: 24.31; SD:

\pm 3.26 ). (Table 2). Based on the overall scores, the health status was deemed to be 'good' (scores 28-55) in $35.5 \%(n=257)$ of the participants, moderate (scores $56-83)$ in $24.6 \%(n=178)$ participants, and poor (Scores $\geqq 84)$ in $39.9 \%(n=289)$ participants. The most common areas reported indicating poor health status were: "Been satisfied with the way you have carried out your tasks" (Mean 2.89; SD \pm 1.14 ) "Been feeling capable of making decisions about things," (Mean 2.86; SD \pm 1.14 ) "Been managing to keep yourself busy and occupied," (Mean 2.41; SD \pm 1.09 ) "Been feeling everything is getting on top of you." (Mean2.77; SD \pm 1.21) (Table 3). 
Table 2

Students' health status scores on individual domains

\begin{tabular}{|c|c|c|c|c|c|c|c|c|}
\hline \multirow[t]{2}{*}{ Domain } & \multicolumn{2}{|c|}{$\begin{array}{l}\text { Good } \\
\text { (Scores 28-55) } \\
(35.5 \%, n=257)\end{array}$} & \multicolumn{2}{|c|}{$\begin{array}{l}\text { Moderate } \\
\text { (Scores } 56-83) \\
(24.6 \%, n=178)\end{array}$} & \multicolumn{2}{|c|}{$\begin{array}{l}\text { Poor } \\
\text { (Scores } \geqq 84) \\
(39.9 \%, n=289)\end{array}$} & \multicolumn{2}{|c|}{$\begin{array}{l}\text { Overall } \\
(n=724)\end{array}$} \\
\hline & $M \pm S D$ & Range & $\mathrm{M} \pm \mathrm{SD}$ & Range & $M \pm S D$ & Range & $\mathrm{M} \pm \mathrm{SD}$ & Range \\
\hline $\begin{array}{l}\text { Somatic } \\
\text { symptoms }\end{array}$ & $\begin{array}{l}10.11 \pm \\
3.36\end{array}$ & $7-22$ & $\begin{array}{l}18.33 \pm \\
4.32\end{array}$ & $7-34$ & $\begin{array}{l}23.57 \pm \\
3.86\end{array}$ & $\begin{array}{l}16- \\
67\end{array}$ & $\begin{array}{l}17.45 \\
\pm 6.74\end{array}$ & $7-35$ \\
\hline $\begin{array}{l}\text { Anxiety and } \\
\text { insomnia }\end{array}$ & $\begin{array}{l}9.69 \pm \\
3.42\end{array}$ & $7-23$ & $\begin{array}{l}19.8 \pm \\
4.42\end{array}$ & $7-30$ & $\begin{array}{l}24.97 \pm \\
4.35\end{array}$ & $\begin{array}{l}19- \\
68\end{array}$ & $\begin{array}{l}18.24 \\
\pm 7.60\end{array}$ & $7-35$ \\
\hline $\begin{array}{l}\text { Social } \\
\text { dysfunction }\end{array}$ & $\begin{array}{l}11.05 \pm \\
4.13\end{array}$ & $7-23$ & $\begin{array}{l}19.76 \pm \\
4.23\end{array}$ & $9-45$ & $\begin{array}{l}24.31 \pm \\
3.26\end{array}$ & $\begin{array}{l}15- \\
35\end{array}$ & $\begin{array}{l}18.47 \\
\pm 6.87\end{array}$ & $7-35$ \\
\hline $\begin{array}{l}\text { Severe } \\
\text { depression }\end{array}$ & $\begin{array}{l}7.77 \pm \\
2.24\end{array}$ & $7-21$ & $\begin{array}{l}12.44 \pm \\
5.16\end{array}$ & $7-25$ & $\begin{array}{l}20.93 \pm \\
4.35\end{array}$ & $8-35$ & $\begin{array}{l}14.17 \\
\pm 7.03\end{array}$ & $7-35$ \\
\hline
\end{tabular}


Table 3

Students' health status scores on individual items

\section{Health status factor/item}

I. Somatic symptoms

1. Been feeling perfectly well and in good health?

2. Been feeling in need of a good tonic?

3. Been feeling run down and out of sorts?

4. Been feeling that you are ill?

5 . Been getting any pains in your head?

6. Been getting a feeling of tightness or pressure in your head?

7. Been having hot or cold spells?

II. Anxiety and insomnia

8.Been losing much sleep over worry?

9.Been having difficulty in staying asleep once you fall asleep?

10.Been feeling constantly under strain?

11.Been getting edgy or bad tempered?

12.Been getting scared or panicky for no reason?

13.Been feeling everything is getting on top of you?

14.Been feeling nervous and strung-out all the time?

\section{Social dysfunction}

15.Been managing to keep yourself busy and occupied?

16.Been taking longer over the things you do?

17.Been satisfied with the way you have carried out your tasks?

18. Been feeling capable of making decisions about things?

19.Been able to enjoy your normal day-to-day activities?
M SD Range

ranking

Factor ranking

\begin{tabular}{llll}
2.71 & 1.09 & $1-5$ & 7 \\
\hline 2.35 & 1.19 & $1-5$ & 19 \\
2.49 & 1.16 & $1-5$ & 12 \\
2.71 & 1.15 & $1-5$ & 6 \\
2.46 & 1.17 & $1-5$ & 16 \\
2.60 & 1.22 & $1-5$ & 11
\end{tabular}

$2.14 \quad 1.08 \quad 1-5$

22 


\begin{tabular}{|c|c|c|c|c|c|}
\hline Health status factor/item & M & SD & Range & $\begin{array}{l}\text { Item } \\
\text { ranking }\end{array}$ & $\begin{array}{l}\text { Factor } \\
\text { ranking }\end{array}$ \\
\hline $\begin{array}{l}\text { 20.Been managing to keep yourself busy and } \\
\text { occupied? }\end{array}$ & 2.41 & 1.09 & $1-5$ & 18 & \\
\hline 21.Been taking longer over the things you do? & 2.29 & 1.12 & $1-5$ & 20 & \\
\hline IV. Severe depression & & & & & 4 \\
\hline $\begin{array}{l}\text { 22.Been thinking of yourself as a worthless } \\
\text { person? }\end{array}$ & 2.11 & 1.11 & $1-5$ & 23 & \\
\hline 23.Been feeling that life is entirely hopeless? & 2.10 & 1.12 & $1-5$ & 24 & \\
\hline 24.Been feeling that life is not worth living? & 2.06 & 1.11 & $1-5$ & 25 & \\
\hline $\begin{array}{l}\text { 25.Been thinking of the possibility that you may do } \\
\text { away with yourself? }\end{array}$ & 1.94 & 1.06 & $1-5$ & 26 & \\
\hline $\begin{array}{l}\text { 26.Been feeling at times that you could not do } \\
\text { anything because your nerves were too bad? }\end{array}$ & 2.24 & 1.18 & $1-5$ & 21 & \\
\hline $\begin{array}{l}\text { 27.Been finding yourself wishing you were dead } \\
\text { and away from it all? }\end{array}$ & 1.87 & 1.05 & $1-5$ & 27 & \\
\hline $\begin{array}{l}\text { 28. Been finding that the idea of taking your own } \\
\text { life keeps coming into your mind? }\end{array}$ & 1.85 & 1.03 & $1-5$ & 28 & \\
\hline Overall & 68.4 & 25.75 & $\begin{array}{l}28- \\
139\end{array}$ & - & - \\
\hline
\end{tabular}

\section{The perceived stress of clinical practice among nursing students}

The perceived stress of clinical practice scores ranged from 0-95 points with an average score of 36.65 (SD \pm 15.95$)$. Stress was mild (average single-item score, 1 point) in $26.7 \%(n=193)$ of students, moderate (average single-item score, 1.5 points) in $64.5 \%(n=467)$ of students, and moderate to severe (average single-item score $>1.5$ points) in $8.8 \%(n=64)$ of students (Table 4$)$. On average, highest scores were reported on domains of stress of 'taking care of patients' (Mean:12.83; SD: \pm 5.14 ) and the 'stress from assignments and workload' (Mean:7.62; SD: \pm 3.91 ) 'teachers and nursing personnel'(Mean:5.90; SD: \pm 3.47 ) (Table 4). 
Table 4

Areas of stress perceived by students - findings from ANOVA

\begin{tabular}{|c|c|c|c|c|c|c|c|c|c|}
\hline & \multicolumn{2}{|c|}{$\begin{array}{l}\text { Mild } \\
\text { (Scores 0-29, } \\
n=193)\end{array}$} & \multicolumn{2}{|c|}{$\begin{array}{l}\text { Moderate } \\
\text { (Scores } 30-43 \text {, } \\
n=467 \text { ) }\end{array}$} & \multicolumn{2}{|c|}{$\begin{array}{l}\text { Moderate to } \\
\text { Severe (Scores } \geqq \\
44, n=64)\end{array}$} & \multicolumn{2}{|c|}{$\begin{array}{l}\text { Overall } \\
(n=724)\end{array}$} & \multirow[t]{2}{*}{$p$} \\
\hline & $\begin{array}{l}M \pm \\
S D\end{array}$ & Range & $\begin{array}{l}M \pm \\
S D\end{array}$ & Range & $\mathrm{M} \pm \mathrm{SD}$ & Range & $\begin{array}{l}\mathrm{M} \pm \\
\mathrm{SD}\end{array}$ & Range & \\
\hline $\begin{array}{l}\text { Taking care of } \\
\text { patients }\end{array}$ & $\begin{array}{l}7.51 \\
\pm \\
3.82\end{array}$ & $0-17$ & $\begin{array}{l}14.02 \\
\pm 3.50\end{array}$ & $5-23$ & $\begin{array}{l}20.83 \pm \\
4.91\end{array}$ & $\begin{array}{l}13- \\
48\end{array}$ & $\begin{array}{l}12.83 \\
\pm 5.14\end{array}$ & $0-29$ & .00 \\
\hline $\begin{array}{l}\text { Teachers and } \\
\text { nursing } \\
\text { personnel }\end{array}$ & $\begin{array}{l}2.38 \\
\pm \\
1.84\end{array}$ & $0-8$ & $\begin{array}{l}6.54 \\
\pm 2.35\end{array}$ & $0-17$ & $\begin{array}{l}11.89 \pm \\
3.03\end{array}$ & $5-19$ & $\begin{array}{l}5.90 \\
\pm 3.47\end{array}$ & $0-19$ & .00 \\
\hline $\begin{array}{l}\text { Assignments } \\
\text { and workload }\end{array}$ & $\begin{array}{l}3.47 \\
\pm \\
2.37\end{array}$ & $0-11$ & $\begin{array}{l}8.44 \\
\pm 2.64\end{array}$ & $3-19$ & $\begin{array}{l}14.11 \pm \\
2.44\end{array}$ & $9-20$ & $\begin{array}{l}7.62 \\
\pm 3.91\end{array}$ & $0-20$ & .00 \\
\hline $\begin{array}{l}\text { Peers and daily } \\
\text { life }\end{array}$ & $\begin{array}{l}1.17 \\
\pm \\
1.29\end{array}$ & $0-6$ & $\begin{array}{l}3.51 \\
\pm 1.84\end{array}$ & $0-9$ & $\begin{array}{l}6.72 \pm \\
2.75\end{array}$ & $0-14$ & $\begin{array}{l}3.17 \\
\pm 2.36\end{array}$ & $0-14$ & .00 \\
\hline $\begin{array}{l}\text { Lack of } \\
\text { professional } \\
\text { knowledge and } \\
\text { skills }\end{array}$ & $\begin{array}{l}2.19 \\
\pm \\
1.52\end{array}$ & $0-6$ & $\begin{array}{l}4.70 \\
\pm 1.56\end{array}$ & $0-15$ & $7 \pm 1.38$ & $3-10$ & $\begin{array}{l}4.22 \\
\pm 2.03\end{array}$ & $0-10$ & .00 \\
\hline $\begin{array}{l}\text { The clinical } \\
\text { environment }\end{array}$ & $\begin{array}{l}.88 \pm \\
1.14\end{array}$ & $0-4$ & $\begin{array}{l}3.24 \\
\pm 1.45\end{array}$ & $0-8$ & $\begin{array}{l}6.23 \pm \\
1.89\end{array}$ & $2-10$ & $\begin{array}{l}2.88 \\
\pm 2.04\end{array}$ & $0-10$ & .00 \\
\hline
\end{tabular}

Situations that were perceived as most stressful for students were in the area of providing care to patients especially the 'lack of experience and ability in providing nursing care and in making judgments', (Mean1.94; SD \pm 0.89 ) 'inability to reach one's expectations dealing with challenges arising from the gap between clinical performance and self-expectation' (Mean1.87; SD \pm 0.92 ,) 'inability to provide appropriate responses to doctors', teachers', and patients' question' (Mean1.77; SD \pm 0.81 ,). Worry about grades was also an area of relatively more perceived stress for students (Mean1.76; SD \pm 1.08 ). The domains that were perceived to cause the least stress were the stress from the environment and stress from peers and daily life (Table 5). 
Table 5

Sources of stress perceived by nursing students

Stress factor/item
$M \quad S D$ Range
Item
ranking

Factor ranking

\section{Stress from taking care of patients}

Lack of experience and ability in providing nursing care and in making judgments (Q2)

Lack of knowledge about how to help patients with physio-psycho-social problems(Q3)

Do not know how to communicate with patients(Q4)

$1.41 \quad 0.86 \quad 0-4 \quad 13$

$1.41 \quad 0.86 \quad 0-4 \quad 13$

Worry about not being trusted or accepted by patients

or patients' family(Q8)

$\begin{array}{llll}1.47 & 0.91 & 0-4 & 11\end{array}$

Experience difficulties in changing from the role of a student to that of a nurse(Q9)

Inability to provide appropriate responses to doctors', teachers', and patients' question(Q10)

Inability to reach one's expectations dealing with challenges arising from the gap between clinical performance and self-expectation (Q11)

Unable to provide patients with good nursing care(Q12)

$1.94 \quad 0.89 \quad 0-4 \quad 1$

$\begin{array}{llll}1.74 & 0.89 & 0-4 & 5\end{array}$

$\begin{array}{llll}1.47 & 0.91 & 0-4 & 11\end{array}$

$\begin{array}{llll}1.12 & 0.85 & 0-4 & 17\end{array}$

$1.77 \quad 0.81 \quad 0-4 \quad 3$

$\begin{array}{llll}1.87 & 0.92 & 0-4 & 2\end{array}$

\section{Stress from teachers and nursing staff}

Experience discrepancy between theory and practice $\begin{array}{lllll}1.62 & 0.89 & 0-4 & 7\end{array}$ (Q1)

Feel that teachers do not give fair evaluation on students (Q14)

Medical personnel lack empathy and are not willing to help(Q17)

Do not know how to discuss patients' illness with teachers, and medical and nursing personnel(Q18)

Feel stressed that teacher's instruction is different from one's expectations(Q20)

Lack of care and guidance from teachers(Q25)

$\begin{array}{llll}0.73 & 0.78 & 0-4 & 26\end{array}$

$\begin{array}{llll}1.50 & 0.76 & 0-4 & 9\end{array}$

$\begin{array}{llll}1.62 & 0.89 & 0-4 & 7\end{array}$

$0.73 \quad 0.78 \quad 0-4 \quad 26$

$\begin{array}{llll}0.72 & 0.73 & 0-4 & 27\end{array}$

$\begin{array}{llll}1.12 & 0.85 & 0-4 & 18\end{array}$

$1.04 \quad 0.81 \quad 0-4 \quad 19$

$\begin{array}{llll}0.68 & 0.73 & 0-4 & 28\end{array}$


Table 5

(Continued).

III. Stress from assignments and workload

Worry about bad grades(Q13)

$\begin{array}{llll}1.76 & 1.08 & 0- & 4 \\ & & 4\end{array}$

Feel that the requirements of clinical practice exceed one's

physical and emotional endurance (Q15)

$\begin{array}{llll}1.34 & 0.88 & 0- & 14\end{array}$

4

Experience pressure from the nature and quality of clinical practice (Q16)

$1.70 \quad 1.09 \quad 0-\quad 6$

4

Feel that dull and inflexible clinical practice affects one's family and social life (Q19)

$\begin{array}{llll}1.49 & 1.05 & 0- & 10 \\ 4 & & 4\end{array}$

Feel that one's performance does not meet teachers' expectations (Q22)

1.31

0.88

$0-\quad 15$

4

V. Stress from peers and daily life

Feel that clinical practice affects one's involvement in extracurricular activities (Q5)

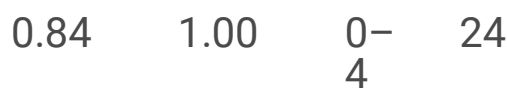

Feel pressure from teachers who evaluate students' performance by comparison (Q21)

0.76

$0.79 \quad 0-\quad 25$

Cannot get along with other peers in the group(Q23)

0.67

$0.73 \quad{ }^{0-}$

29

Experience competition from peers in school and clinical practice(Q24)

0.89

$0.81 \quad 0-$

23

4

\section{Stress from lack of professional knowledge and skills}

Unfamiliar with patients' diagnoses and treatments(Q6)

1.42

$\begin{array}{lll}0.76 & 0- & 12 \\ & 4\end{array}$

Unfamiliar with medical history and terms(Q7)

1.51

$\begin{array}{lll}0.82 & 0- & 8 \\ & 4\end{array}$

Unfamiliar with professional nursing skills(Q26)

\begin{tabular}{|c|c|}
\hline 1.29 & 0.83 \\
\hline
\end{tabular}

\section{Stress from the environment}

Feel stressed from the rapid change in patient's condition(Q27)

Unfamiliar with the ward facilities(Q28)

0.95

0.93

0.72

4

22

\section{takes place(Q29)}

Feel stressed in the hospital environment where clinical practice

1.00

Overall

$\begin{array}{lllll}36.65 & 15.95 & 0- & - & - \\ & & 95 & & -\end{array}$




\section{Correlation between nursing students' health status and the level of stress}

In the unadjusted analysis of liner correlation between health status and perceived stress, health status was highly positively correlated with the level of stress $(r=.665, p<.01)$; the more severe the health problems were, the greater the perceived stress was (Table 6).

Table 6

Adjusted analysis of the correlation of health status with internship stress $(\mathrm{N}=724)$

\begin{tabular}{|llll|}
\hline & Average & Standard deviation & R \\
\hline Health status & 68.40 & 25.75 & $.665^{\star}$ \\
\hline Internship stress & 36.65 & 15.95 & \\
\hline$* p<.01$. & & & \\
\hline
\end{tabular}

A number of factors including health status, practice subject, practice grade, gender, and sleeping hours were adjusted in the multivariate regression analysis. The variables that showed statistically significant associations were general health status, practice subject, practice grade, gender, sleeping hours in particular order. Among all the variables, health status had the most significant correlation to perceived stress $(p<.000)$. Among various practice areas, the areas with significant correlation were Medical Surgical Nursing $(p=.002)$ and Obstetrics and Paediatric Nursing $(p=.007)$. Practice grade $(p<.000)$, gender $(p=.013)$ and sleeping hours $(p=.046)$ also showed significant correlation. In the adjusted analysis, the association between health status remained significant $(p<.001 ; R 2=.50)$ (Table 7). 
Table 7

Multivariate regression analysis of association between individual factors and perceived stress $(\mathrm{N}=724)$

\begin{tabular}{|c|c|c|c|c|}
\hline Independent variable & $\beta$ & SE & $\mathbf{t}$ & $\mathbf{p}$ \\
\hline Health status & .61 & .018 & 21.25 & .000 \\
\hline \multicolumn{5}{|l|}{ Practice subject } \\
\hline Medical Surgical nursing Practicum & .10 & 1.43 & 3.12 & .002 \\
\hline Obstetrics, Pediatricnursing Practicum & .08 & 1.01 & 2.71 & .007 \\
\hline Psychiatric, Communitynursing Practicum & NS & NS & NS & NS \\
\hline Long-Term care Practicum & .004 & 1.36 & .14 & .893 \\
\hline Practice Grade & .15 & 1.12 & 5.36 & .000 \\
\hline Gender & .07 & 2.37 & 2.50 & .013 \\
\hline Sleeping hours & .06 & .85 & 2.00 & .046 \\
\hline R2 & .50 & & & \\
\hline Adj R2 & .49 & & & \\
\hline \multicolumn{5}{|l|}{${ }^{\star} \mathrm{p}<.05 .{ }^{* \star} \mathrm{p}<.01 .{ }^{* \star \star} \mathrm{p}<.001}$. \\
\hline \multicolumn{5}{|l|}{ Stress } \\
\hline \multicolumn{5}{|l|}{$\leqq 65.5>65.5$} \\
\hline \multicolumn{5}{|l|}{$\leqq 34.5>34.5 \leqq 93.5>93.5$} \\
\hline$\leqq 84.5>84.5$ & & & & \\
\hline
\end{tabular}

\section{A model for predicting perceived stress of clinical practice among nursing students: findings from the CART analysis}

The CART analysis produced a tree model with three branches and five terminal nodes with values predicting perceived stress. The results of the CART analysis are shown in Fig. 1. The most appropriate tree for predicting perceived stress of clinical practice consisted of eight nodes and five terminal nodes. On the basis of the minimum Gini improvement measure of perceived stress, we found that general health status was the best predictor in the first layer. The general health status score, predicted score for perceived stress, and population size respectively were $<34.5,17.06$, and 104 at node $3 ;<34.5,31.63$, 
210 at node $4 ; \leqq 84.5,38.02$, and 170 at node $7 ;>84.5,44.19$, and 130 at node 8 ; and $>93.5,53.75$, and 110 at node 6 . Those who were in excellent (GHQ-28 score $\leq 34.5$ ) or good (GHQ-28 score $>34.5-<84.5$ ) health status, reported mild or moderate stress with a health status score of 84.5 as the point of transition to severe stress. When health status score was greater than 84.5 , perceived stress was at a severe or extremely severe level, indicating that health status was the most predictive factor (Fig. 1).

\section{Discussion}

This study aimed to examine factors associated with perceived stress during clinical practice among nursing students, and to investigate whether a decision-tree could be used to develop an accurate prediction model for perceived stress with a focus on the effect of health status on perceived stress.

More than one third of the students in our study reported poor health status, with the domains of anxiety and insomnia and social dysfunction as the poorest areas of health with dissatisfaction expressed in aspects such as the way tasks were carried out, inability to make decisions, managing to keep themselves busy and occupied, and feeling that everything is getting on top of them. General health is one of the most important factors of student success and academic achievement and nursing students' general health status during clinical placement will have a great impact on students' clinical performance, and overall achievement of the learning outcomes. It has been recognised that the health and well-being of student nurses is of considerable importance given the demands posed by the course and the profession, as well as the implications on providing good quality care [47].

Majority of the students in our study experienced moderate to severe levels of stress, with the highest stress experienced in the domains of patient care, assignments and workload and teachers and nursing personnel. Studies have suggested that clinical placements are substantial sources of stress for nursing students $[4,10-15,27]$. Previous researchers have reported specific stressors such as the gap between theory and practice, feelings of lack of preparation for practice or to cope with knowledge and skill demands, fear of making mistakes, fear of death and dying, problematic interpersonal relationships with clinical teachers and nursing staff, lack of familiarity with the clinical environment, and conflicts between professional beliefs and the reality in hospital practice [27, 48-49]. Previous studies from Taiwan have indicated the link between low interest in clinical practicum placement and increased stress levels in nursing students [50]. The students in our study perceived factors such as lack of experience and ability in providing nursing care and in making judgments, expectations dealing with challenges arising from the gap between clinical performance and self-expectation, lack of knowledge about how to help patients with physio-psycho-social problems and worry about grades as the predominant sources of stress. Although some of these stressors were unavoidable due to students' limited professional knowledge and clinical skills, the findings indicated the need for teachers and placement supervisors to provide better guidance to students and to prepare them adequately for clinical practice in order to minimise the stress experienced by students. 
A number of studies have reported the clinical environment as a key source of stress for students [27$28,33,51-52$ ]. This was not the case for the participants in our study as we found that the domains that were perceived to cause the least stress for our participants were the stress from the environment and stress from peers and daily life. Similar findings have been reported among nursing students in Taiwan who had completed their initial clinical practice at the largest nursing school [32].

We found that the overall health status was the most significant predictor to the level of stress experienced by the students; the more severe the health problems were, the greater the perceived stress was. As previous studies have not focused on the effect of health status on perceived stress during clinical practice in Taiwanese or other similar settings, it is difficult to directly compare the findings with those from previous studies. The link between current health status scores and vulnerability to stress that we found in our study is an important finding as this measure enables to identify students who are most vulnerable to stress.

A major limitation of this study was the use of convenience sampling and the lack of diversity as participants were recruited from the associate degree nursing program in one nursing school and this could limit the wider applicability of the findings. In addition, the cross-sectional nature study would have limited the casual inferences between health status and perceived stress. The use of self-reported data might have also affected the validity of the findings.

\section{Conclusion}

Overall, the findings from the current study provided key insights into the factors associated with perceived stress of clinical practice among final year nursing students in Taiwan and demonstrated the link between health status and vulnerability to stress. The study also added to the existing body of evidence about the potential use of GHQ-28 to assess nursing students' vulnerability to stress during clinical placement and how general health status could be used as a measure to predict vulnerability to stress and to identify students who are most vulnerable.

The findings have important implications for nursing educators as well as placement supervisors in identifying and supporting students who are vulnerable to experience stress during clinical practice. As some of the stressors are inevitable, nursing students should be provided with appropriate educational as well as other evidence based interventions towards boosting their general health and well-being during clinical placement thereby enhancing their ability to cope with the stress of clinical practice. As the health of an individual is dependent upon a range of internal and external factors, it is of considerable importance to examine and continuously monitor factors that contribute to poor health at an individual level throughout their studies as well as during the practicum.

The psycho-social support from peers and family members is another aspect to consider and build on when planning psychosocial intervention programmes. Future studies should examine the longitudinal link between health status and perceived stress as well as explore coping behaviours at different stages of clinical placement and the feasibility of introducing appropriate longitudinal interventions. The 
perspectives of educators and placement supervisors about potential sources of stress are also worth exploration.

\section{Declarations}

\section{Ethics approval and consent to participate}

Ethics approval from the Ethics Committee of National Cheng Kung University (NCKU HREC-E-105-113-2).

\section{Consent for publication}

The manuscript does not contain any individual person's data in any form.

\section{Availability of data and material}

\section{Competing interests}

No authors of this study have personal, professional, or financial conflicts of interest to declare.

\section{Funding}

This study received an funding provided by National Tainan Junior College of Nursing with grant number: 105002.

\section{Acknowledgements}

We express our sincere gratitude to all of the participants for providing their time and energy to this project without which this study would not have been possible. In addition, we express our sincere gratitude to the grant of National Tainan Junior College of Nursing for supporting this study.

\section{Authors' contributions}

CsW led the study design, data collection, data analysis, interpretation and manuscript preparation; JrR and $\mathrm{MzH}$ contributed to the data analysis, interpretation and manuscript preparation; All authors read and approved the final manuscript.

\section{References}


1. Levett-Jones T, Lathlean J, Higgins I, McMillan M. The duration of clinical placements: a key influence on nursing students' experience of belongingness. Aust J Adv Nurs. 2008;26:8-16.

2. Andersson PL, Edberg AK. The transition from rookie to genuine nurse: narratives from Swedish nurses 1 year after graduation. J Contin Educ Nurs. 2010;41:186-92.

3. Duffy JR. Want to graduate nurses who care? Assessing nursing students' caring competencies. Annual Review of Nursing Education. 2005;3:59-76.

4. Morrell N, Ridgway V. Are we preparing student nurses for final practice placement? British journal of nursing. 2014;23:518-23.

5. Abdelsalam G, Basal AA, Ebrahem RA, Elnagar SA. Perceptions of role transition among nursing interns at Tanta University. J Nurs Health Sci. 2016;5:16-22.

6. Levett-Jones T, Pitt V, Courtney-Pratt H, Harbrow G, Rossiter R. What are the primary concerns of nursing students as they prepare for and contemplate their first clinical placement experience? Nurse Educ Pract. 2015;15:304-9.

7. Jewell A. Supporting the novice nurse to fly:A literature review. Nurse Educ Pract. 2013;13:323-7.

8. Teoh YTE, Pua LH, Chan MF. Lost in transition-A review of qualitative literature of newly qualified Registered Nurses' experiences in their transition to practice journey. Nurs Educ Today. 2013;33:1437.

9. Casey D, Burke E, Houghton C, Mee L, Smith R, Van Der Putten D, Bradley H, Folan M. Use of peer assessment as a student engagement strategy in nurse education. Nurs Health Sci. 2011;13:514-20.

10. Li PW. The Association Study Between Nurses' Job Stress and Physical-Mental Health Unpublished master dissertation. Tzu Chi University; 2006.

11. Moscaritolo LM. Interventional strategies to decrease nursing student anxiety in the clinical learning environment. J Nurs Educ. 2009;48:17-23.

12. Pulido-Martos M, Augusto-Landa JM, Lopez-Zafra E. Sources of stress in nursing students: a systematic review of quantitative studies. Int Nurs Rev. 2012;59:15-25.

13. Sharif $F$, Masoumi S. A qualitative study of nursing student experiences of clinical practice. BMC Nurs. 2005;4:1-7.

14. Sheu S, Lin HS, Hwang SL. The relationships among stress, physio-psycho-social status, coping behaviors and personality traits of nursing students during first time clinical practice. Nurs Res. 2001;9:233-46.

15. Wang HP, Kao YH. The Study on Learning Difficulties of Clinical Practice for Students of 5-year Junior Colleges of Nursing. Tzu Chi Nursing Journal. 2010;2:71-82.

16. Sun FK, Long A, Tseng YS, Huang HM, You JH, Chiang CY. Undergraduate student nurses' lived experiences of anxiety during their first clinical practicum: A phenomenological study. Nurs Educ Today. 2016;37:21-6.

17. Rajeswaran L. Clinical experiences of nursing students at a selected institute of health sciences in Botswana. Health Sci J. 2016;10:1-6. 
18. Hung $\mathrm{CH}$, Chen CS. Occupational therapy students' fieldwork perception in a junior college. Journal of Taiwan Occupational Therapy Research Practice. 2006;2:29-39.

19. Singh N, Kohli C. Stress reaction and coping strategies among nursing students in Delhi. Asian J Nur Edu Research. 2015;5:274-8.

20. Baghurst T, Kelley BC. An examination of stress in college students over the course of a semester. Health Promot Pract. 2014;15:438-47.

21. Demiray A, Korhan EA, Yont GH, Bayraktar D, Khorshid L. The Reliability of the Turkish Version of the Stressors in Students Scale. Int J Caring Sci. 2017;10:1360-7.

22. Huang YW, Yang CH, Ho SL, Hwu YJ. The relationship between practicum-related stress and sleep quality in nursing students. J Nurs Health Res. 2011;7:14-25.

23. Jimenez C, Navia-Osorio PM, Diaz CV. Stress and health in novice and experienced nursing students. J Adv Nurs. 2010;66:442-55.

24. Oner Altiok H, Ustun B. The Stress Sources of Nursing Students. Educational Sciences: Theory Practice. 2013;13:760-6.

25. Wang CL, Lee HL, Lu KY. Nursing student depression and associated factors during students' first clinical practice. J Nurs Healthc Res. 2010;6:65-75.

26. Watson R, Deary I, Thompson D, Li G. A study of stress and burnout in nursing students in Hong Kong: a questionnaire survey. Int J Nurs Stud. 2008;45:1534-42.

27. Chernomas WM, Shapiro C. Stress, depression, and anxiety among undergraduate nursing students. Int J Nurs Educ Scholarsh. 2013;10:255-66.

28. Wolf L, Stidham AW, Ross R. Predictors of stress and coping strategies of US accelerated vs generic baccalaureate nursing students: An embedded mixed methods study. Nurs Educ Today. 2015;35:201-5.

29. Chen YH, Chen KY, Lin PC. Nursing Students' Perceptions of Stress and Coping Behaviors During the Initial Clinical Practice Period. Journal of Bulletin of Chung Hwa University of Medical Technology. 2013;39:69-90.

30. Ministry of Examination ROC. Professional and technical personnel examinations act enforcement rules. https://wwwc.moex.gov.tw/english/content/wfrmContent.aspx?me nu_id = 452. 2020.

31. Tseng HC, Wang HH, Weng WC. Nursing students' perceptions toward the nursing profession from clinical practicum in a baccalaureate nursing program-A qualitative study. Kaohsiung J MED SCI. 2013;29:161-8.

32. Sheu S, Lin HS, Hwang SL. Perceived stress and physio-psycho-social status of nursing students during their initial period of clinical practice: the effect of coping behaviors. Int J Nurs Stud. 2002;39:165-75.

33. Chen $\mathrm{YW}$, Hung $\mathrm{CH}$. Predictors of Taiwanese baccalaureate nursing students' physio-psycho-social responses during clinical practicum. Nurs Educ Today. 2014;34:73-7. 
34. Ministry of Education. Number of students in colleges and universities. https://depart.moe. edu.tw/ED4500/News_Content.aspx? $\mathrm{n}=$ 5A930C32CC6C3818\&sms $=$ 91B3AAE8C6388B96\&s $=$ 596D9D77281BE257. 2019.

35. Lemeshow S, Hosmer DW, Klar J, Lwanga SK. World Health Organization. Adequacy of sample size in health studies. Chichester: Wiley; 1990.

36. Sheu S, Lin HS, Hwang SL, Yu PJ, Hu WY, Lou MF. The Development and Testing of a Perceived Stress Scale for Nursing Students in Clinical Practice. Nurs Res. 1997;4:341-52.

37. Goldberg DP, Hillier VF. A scaled version of the General Health Questionnaire. Psychol Med. 1979;9:139-45.

38. Chan DW. The two scaled versions of the Chinese General Health Questionnaire: A comparative analysis. Soc Psych Psych Epid. 1995;30:85-91.

39. Ardakani A, Seghatoleslam T, Habil H, Jameei F, Rashid R, Zahirodin A, Arani AM. Construct validity of symptom checklist-90-revised (SCL-90-R) and general health questionnaire-28 (GHQ-28) in patients with drug addiction and diabetes, and normal population. Iran J Public Health. 2016;45:451-9.

40. de Kock FS, Görgens-Ekermans G, Dhladhla TJ. A confirmatory factor analysis of the General Health Questionnaire-28 in a Black South African sample. J Health Psychol. 2014;19:1222-31.

41. Molina JD, Andrade-Rosa C, González-Parra S, Blasco-Fontecilla H, Real MA, Pintor C. The factor structure of the General Health Questionnaire (GHQ): a scaled version for general practice in Spain. Eur Psychiat. 2006;21:478-86.

42. Breiman L, Friedman JH, Olshen RA, Stone CJ. Classification and Regression Trees. New York: Chapman and Hall; 1984.

43. Zhang B, Wei Z, Ren J, Cheng Y, Zheng Z. An empirical study on predicting blood pressure using classification and regression trees. IEEE Access. 2018;6:21758-68.

44. Li X, Dusseldorp E, Meulman JJ. Meta-CART: A tool to identify interactions between moderators in meta-analysis. Brit J Math Stat Psy. 2017;70:118-36.

45. Liu Z, Kanter CA, Messer KD, Kaiser HM. Identifying significant characteristics of organic milk consumers: A CART analysis of an artefactual field experiment. Appl Econ. 2013;45:3110-21.

46. Kass GV. An exploratory technique for investigating large quantities of categorical data. J Roy Stat Soc: Ser C (Appl Stat). 1980;29:119-27.

47. Gray S, Diers D. The effect of staff stress on patient behavior. Arch Psychiat Nurs. 1992;6:26-34.

48. Evans W, Kelly B. Pre-registration diploma student nurse stress and coping measures. Nurs Educ Today. 2004;24:473-82.

49. Admi $H$, Moshe-Eilon $Y$, Sharon $D$, Mann M. Nursing students' stress and satisfaction in clinical practice along different stages: A cross-sectional study. Nurs Educ Today. 2018;68:86-92.

50. Perng SJ, Sung HC, Chen CJ, Lee TY, Koo M. Low interest in clinical practicum placement is associated with increased stress in nursing students in Taiwan: A cross-sectional survey study. Nurs 
Educ Today. 2020;84:1-5.

51. Suresh P, Matthews A, Coyne I. Stress and stressors in the clinical environment: a comparative study of fourth-year student nurses and newly qualified general nurses in Ireland. J Clin Nurs. 2013;22:770-9.

52. McCarthy B, Trace A, O’Donovan M, Brady-Nevin C, Murphy M, O'Shea M, O'Regan P. Nursing and midwifery students' stress and coping during their undergraduate education programmes: An integrative review. Nurs Educ Today. 2018;61:197-209.

\section{Figures}




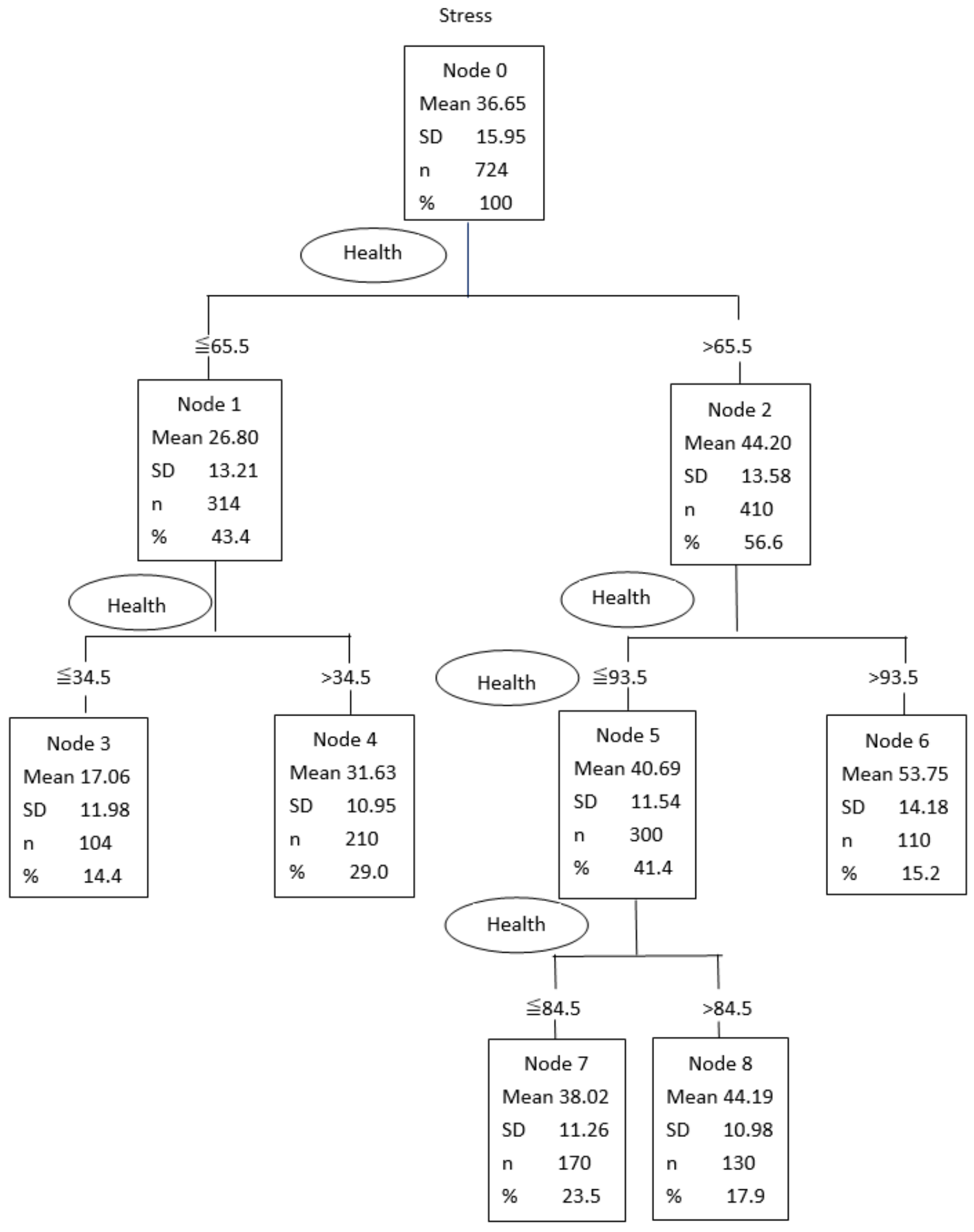

Figure 1

Decision-tree diagram for predicting which nursing students will be most vulnerable to internship stress 